\title{
Differential Responses of the Acidobacterial Community in the Topsoil and Subsoil to Fire Disturbance in Pinus tabulaeformis Stands
}

\author{
Weike Li ${ }^{1}$, Xiaodong Liu ${ }^{\text {Corresp., } 1}$, Shukui Niu ${ }^{\text {Corresp. } 1}$ \\ ${ }^{1}$ The College of Forestry, Beijing Forestry University, Beijing, China \\ Corresponding Authors: Xiaodong Liu, Shukui Niu \\ Email address: xd_liu@bjfu.edu.cn, niushukui@bjfu.edu.cn
}

Acidobacteria is found to be dominant and abundant in forest soil, and performs specific ecological functions (such as cellulose decomposition and photosynthetic capacity, etc.). However, relative limited is known about its changing patterns after a fire interruption. In this study, the response of soil Acidobacteria to a wildfire disturbance was investigated using the Illumina MiSeq sequencing system. The research area was classified by different severities of fire damage (high, moderate, and low severity, and an unburnt area), and samples were collected from various soil layers $(0-10 \mathrm{~cm}$ as topsoil; $10-20 \mathrm{~cm}$ as subsoil). We obtained a total of 986,036 sequence reads; $31.77 \%$ of them belonged to Acidobacteria. Overall, 18 different Acidobacteria subgroups were detected, with subgroups $4,6,1,3$, and 2 the most abundant, accounting for $31.55 \%, 30.84 \%, 17.42 \%$, $6.02 \%$, and $5.81 \%$ of acidobacterial sequences across all samples, respectively. Although no significant differences in acidobacterial diversity were found in the same soil layer across different fire severities, we observed significantly lower numbers of reads, but higher Shannon and Simpson indices, in the topsoil of the high-severity fire area than in the subsoil. Non-metric multidimensional scaling (NMDS) analysis and permutational multivariate analysis of variance (PERMANOVA) also revealed significant differences in the acidobacterial community structure between the two soil layers. Soil pH, total nitrogen, $\mathrm{NH}_{4}{ }^{+} \mathrm{N}$, the Shannon index of understory vegetation and canopy density were the major drivers for acidobacterial community structure in the topsoil, while soil $\mathrm{pH}$ and organic matter were significant factors in the subsoil. A variance partitioning analysis (VPA) showed that edaphic factors explained the highest variation both in the topsoil (15.6\%) and subsoil (56.3\%). However, there are large gaps in the understanding of this field of research that still need to be explored in future studies. 


\section{Differential Responses of the Acidobacterial Community in the Topsoil and Subsoil to Fire Disturbance in Pinus tabulaeformis \\ Stands}

Weike $\mathrm{Li}^{1}$, Xiaodong Liu ${ }^{1}$, Shukui Niu ${ }^{1}$

${ }^{1}$ The College of Forestry, Beijing Forestry University, No. 35 Qinghua East Road, Haidian District, Beijing 100083, China.

Corresponding author:

Xiaodong Liu

Shukui Niu

The College of Forestry, Beijing Forestry University, No. 35 Qinghua East Road, Haidian District, Beijing 100083, China.

Email address: $\underline{x d \_l i u @ b j f u . e d u . c n}$

niushukui@bjfu.edu.cn 


\section{ABSTRACT}

2 Acidobacteria is found to be dominant and abundant in forest soil, and performs specific

3 ecological functions (such as cellulose decomposition and photosynthetic capacity, etc.).

4 However, relative limited is known about its changing patterns after a fire interruption. In this

5 study, the response of soil Acidobacteria to a wildfire disturbance was investigated using the

6 Illumina MiSeq sequencing system. The research area was classified by different severities of

7 fire damage (high, moderate, and low severity, and an unburnt area), and samples were collected

8 from various soil layers ( $0-10 \mathrm{~cm}$ as topsoil; $10-20 \mathrm{~cm}$ as subsoil). We obtained a total of

9986,036 sequence reads; $31.77 \%$ of them belonged to Acidobacteria. Overall, 18 different

10 Acidobacteria subgroups were detected, with subgroups 4, 6, 1, 3, and 2 the most abundant,

11 accounting for $31.55 \%, 30.84 \%, 17.42 \%, 6.02 \%$, and $5.81 \%$ of acidobacterial sequences across

12 all samples, respectively. Although no significant differences in acidobacterial diversity were

13 found in the same soil layer across different fire severities, we observed significantly lower

14 numbers of reads, but higher Shannon and Simpson indices, in the topsoil of the high-severity

15 fire area than in the subsoil. Non-metric multidimensional scaling (NMDS) analysis and

permutational multivariate analysis of variance (PERMANOVA) also revealed significant

differences in the acidobacterial community structure between the two soil layers. Soil $\mathrm{pH}$, total nitrogen, $\mathrm{NH}_{4}{ }^{+}-\mathrm{N}$, the Shannon index of understory vegetation and canopy density were the major drivers for acidobacterial community structure in the topsoil, while soil $\mathrm{pH}$ and organic matter were significant factors in the subsoil. A variance partitioning analysis (VPA) showed that edaphic factors explained the highest variation both in the topsoil (15.6\%) and subsoil (56.3\%). However, there are large gaps in the understanding of this field of research that still need to be explored in future studies.

\section{INTRODUCTION}

Fire is a significant interfering factor in forest ecosystems. Heat from fire has strong direct and indirect effects on vegetation (Knelman et al., 2015), animals (Wang \& Yan, 2017), soil (Mikita- 
27

Barbato et al., 2015), regional climate (Lehmann et al., 2014), and the water cycle (Chen et al., 2013). As an important part of the forest ecosystem, soil microorganisms maintain ecosystem stability through the role in driving organic matter decomposition and soil nutrient cycling (Kristal \& Kathleenk, 2010). Although the response of soil microorganisms to fire disturbance has been studied extensively, the impacts of fire severity on bacterial communities is far from a settled question. Pressler et al. (2018) concluded that there are insufficient studies to draw strong conclusions about the role of fire severity on the bacterial community. Weber et al. (2014) found inconsistent response of bacterial communities to fire severity. However, the above studies focused on the overall changes in bacterial communities. Little attention has been paid to the effects of a wildfire on specific bacterial phyla.

Acidobacteria have been recognized as being ubiquitous and abundant in forest soil (Jones et al., 2009; Mbuthia et al., 2015). Based on 16S rRNA sequencing, $10 \%$ to $50 \%$ of the obtained soil microbial sequences have been assigned to this phylum (Navarrete et al., 2013; Liu et al., 2016). Currently, Acidobacteria are classified into 26 subgroups (Barns et al., 2007); subgroups 1 to 4 and subgroup 6 are found to be predominant in soils (Naether 2012; Zhang et al., 2014). Although bacteria of this phylum are difficult to cultivate (Liu et al., 2016), molecular techniques provide an opportunity to gain an insight into their ecological and physiological characteristics (Kielak et al., 2016). In previous studies, Acidobacteria have been observed to exhibit oligotrophy that is found to be related to some ecosystem processes, such as the decomposition of organic matter and carbon cycling (Jones et al., 2009; Griffiths et al., 2011; Eichorst et al., 2011; Sul et al., 2013) and their phylogenetic diversity is considered to be comparable to that of the phylum Proteobacteria (Liu et al., 2016). However, not all members of the subgroups show consistent biological characteristics. For example, the gene sequences of Acidobacteria are also detected in neutral or even alkaline environments (Xiong et al., 2012). In addition, de Castro et al. (2013) reported that several isolates of this phylum are capable of growth in a eutrophic environment. Furthermore, Belova et al (2018) reported two acidobacterial strains $\left(\mathrm{SBC} 82^{\mathrm{T}}\right.$ and CCO287) were assigned to a novel genus and species and members of this genus colonize acidic 
54

55

56

soils and peatlands and specialize in degrading complex polysaccharides. Hausmann et al (2018) showed by genome-centric metagenomics and metatranscriptomics that members of the Acidobacteria phylum have a putative role in peatland sulfur cycling. Eichorst et al (2018) performed a large-scale comparative genome analysis of acidobacterial subdivisions and observed that low- and high-affinity respiratory oxygen reductases in multiple genomes, suggesting the capacity for growing across different oxygen gradients. They also detected the capacity of many acidobacterial genomes to use multiple carbohydrates as well as inorganic and organic nitrogen sources. Diamond et al (2019) also reported that acidobacteria play important roles in $\mathrm{C}$ cycling in soils.

Studies of the influence of fire on the abundance of Acidobacteria have shown inconsistent results, with reports of a great decrease (Xiang et al., 2014), a significant increase in lightly burnt unvegetated soils (Knelman et al., 2015), and minor changes at the phylum level, but with a significantly lower abundance of subgroup 1 after burning (Shen et al., 2016). The differences in these results may be attributable to the sampling time, location, fire severity, vegetation type, etc., as well as the variable biological characteristics of the Acidobacteria subgroups (Liu et al., 2016). For example, Zhang et al (2014) reported that the relative abundances of subgroup 1, 2, 3 increased with the altitude, but the relative abundances of subgroup 4, 5, 6, 16, 17 decreased with the altitude. Several researchers also found that the effects of soil $\mathrm{pH}$ on Acidobacteria subgroups are not exactly the same (Jones et al., 2009; Turlapati et al., 2013; Kielak et al., 2016). Xiang et al (2014) reported that the relative abundance of Acidobacteria is negatively correlated with soil pH; however, Liu et al. (2016) found a significantly positive relationship between the abundance of Acidobacteria and soil pH. Although significant findings have been made concerning the distribution of Acidobacteria after fire disturbance (Xiang et al., 2014; Shen et al., 2016; Sun et al., 2016), knowledge of the response pattern at the subgroup level is still limited. In this study, we try to control other variables to be unified and mainly to explore the influence of different fire severities on Acidobacteria. 
81

82

Acidobacteria, we aimed to gain an insight into the response of this phylum (especially at the subgroup level) to wildfire. We assessed the response of Acidobacteria to different fire severities (high, moderate and low severity, and unburnt) at two soil depths $(0-10 \mathrm{~cm}$ as the topsoil and 10$20 \mathrm{~cm}$ as the subsoil). We sought to address three questions: (1) How does the acidobacterial community composition vary in the topsoil and subsoil after burning at different severities? (2) What are the main factors that affect changes in soil acidobacterial communities after a wildfire? (3) Are the driving factors in the topsoil and subsoil the same?

\section{MATERIALS \& METHODS}

\section{Site Description and Soil Sampling}

This study was conducted in Pingquan County, Hebei province, northern China $\left(118^{\circ} 22^{\prime} \sim 118^{\circ} 37^{\prime} \mathrm{E}, 41^{\circ} 01^{\prime} \sim 41^{\circ} 21^{\prime} \mathrm{N}\right)$ (Fig. S1). As a typical coniferous tree species in North China, Pinus tabulaeformis is widely distributed in this area (Zhu et al., 2015). The oil content of the branches and leaves of Pinus tabulaeformis is high, and the trees belong to the flammable forest type (Niu, 2011). The soil types were classified as brown soil and cinnamon soil (Li et al., 2015). The climate is semi-humid and semi-humid continental monsoon, with a mean annual temperature of $7.3^{\circ} \mathrm{C}$. The mean annual precipitation in this region is $550 \mathrm{~mm}$, of which $70 \%$ is summer rainfall (July-September) (Li et al., 2015).

In April 2015, a 56.33 ha wildfire occurred in this region. The burned area was divided into different regions according to the fire severity (high, moderate and low severity, and a nearby unburnt area) (Zheng et al., 2012). The percentages of different severity levels are about 55.56\% (high), 33.33\% (moderate), $11.11 \%$ (low). The classification standard of fire severity is shown in Table 1 and we also provide a set of photographs to show the visual perception of different fire severity areas (Fig. 1). Soil samples were collected 6 months after the fire. 
106

107

108

109

110

111

112

113

114

115

116

117

118

119

120

121

122

123

124

125

126

127

128

129

130

Three plots $(20 \mathrm{~m} \times 20 \mathrm{~m})$ were established in each of four distinct patches, representing the different fire intensity levels (high, moderate, low and unburned). There were 12 plots in total, with similar slopes $\left(20 \sim 23^{\circ}\right)$, aspects $\left(37 \sim 42^{\circ}\right)$ and elevations $(1119 \sim 1143 \mathrm{~m})$. In each plot, five random soil cores at a depth of 0-10 $\mathrm{cm}$ and 10-20 cm were taken. Before sample collection, the litter, charred debris, and ash layer were removed. Then, the five soil cores from the same layer were mixed into one soil sample. In total, 24 composite samples (12 topsoil; 12 subsoil) were collected. All samples were transported to the laboratory in an ice box for further analysis. Samples were divided into two parts: one part was stored at $4{ }^{\circ} \mathrm{C}$ for biogeochemical analysis, and the other was stored at $-20^{\circ} \mathrm{C}$ for DNA analysis.

\section{Plant Diversity and Structure and Soil Physicochemical Analyses}

The plant species, plant height, canopy density and tree diameter at breast height ( $\mathrm{DBH}>5 \mathrm{~cm})$ were recorded in each plot (Table S1). Then, ten quadrats were randomly established in each plot (five $1 \times 1 \mathrm{~m}$ quadrants for herbs; five $5 \times 5 \mathrm{~m}$ quadrats for shrubs). The diversity of the understory vegetation (i.e. herbs and shrubs) was evaluated using the Shannon-Wiener index

(H'Vegetation), Simpson index (D'Vegetation) and Pielou's evenness index (J'Vegetation) (Yu et al., Soil moisture (SM) was determined by oven-drying the samples at $105^{\circ} \mathrm{C}$ until they were 2012).

of constant weight. $\mathrm{pH}$ was determined using a $\mathrm{pH}$ meter for a 1:2.5 ratio of fresh soil to deionized water at $20^{\circ} \mathrm{C}$. Soil organic matter $(\mathrm{OM})$ content was measured by dichromate oxidation (Xue et al., 2014), and total nitrogen (TN) was measured with the Kjeldahl method (Walkley \& Black, 1934). The ammonium nitrogen $\left(\mathrm{NH}_{4}{ }^{+}-\mathrm{N}\right)$ and nitrate nitrogen $\left(\mathrm{NO}_{3}{ }^{-}-\mathrm{N}\right)$ contents were also measured (Crooke \& Simpson, 1971; Best, 1976).

\section{DNA Extraction and PCR Amplification}

Genomic DNA was extracted from $0.5 \mathrm{~g}$ of fresh soil using an E.Z.N.A.® soil DNA kit (Omega Bio-tek, Norcross, GA, USA), following the manufacturer's instructions. The quality of the 
131

132

133

134

135

136

137

138

139

140

141

142

143

144

145

146

147

148

149

150

151

152

153

154 155

DNA extracted was checked by $1 \%$ agarose gel electrophoresis and spectrophotometry (the ratio of optical density at $260 \mathrm{~nm} / 280 \mathrm{~nm}$ ). All extracted DNA samples were stored at $-20^{\circ} \mathrm{C}$ for further analysis.

To assess the bacterial composition, the V3-V4 hypervariable regions of the bacterial $16 \mathrm{~S}$ rRNA genes were amplified by PCR $\left(95^{\circ} \mathrm{C}\right.$ for $5 \mathrm{~min} ; 33$ cycles at $95^{\circ} \mathrm{C}$ for $30 \mathrm{~s}, 56^{\circ} \mathrm{C}$ for $30 \mathrm{~s}$ and $72{ }^{\circ} \mathrm{C}$ for $40 \mathrm{~s}$; with a final extension of $72^{\circ} \mathrm{C}$ for $10 \mathrm{~min}$ ), using the universal primers forward 338F (5'-ACTCCTACGGGAGGCAGCAG-3') and reverse 806R (5'GGACTACHVGGGTWTCTAAT-3') (Liu et al., 2018). These primers contained an 8 nucleotide barcode sequence unique to each sample. PCR reactions were performed in triplicate in a $50 \mu \mathrm{L}$ mixture containing $5 \mu \mathrm{L}$ of $10 \times$ Pyrobest Buffer, $4 \mu \mathrm{L}$ of $2.5 \mathrm{mM}$ dNTPs, $2 \mu \mathrm{L}$ of

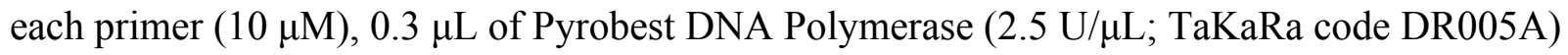
and $30 \mathrm{ng}$ of template DNA. Then, the mixture was used to perform sequencing. The raw reads were deposited into the National Center for Biotechnology Information Sequence Read Archive database (accession number: SRP158101).

\section{Illumina MiSeq Sequencing}

Amplicons were extracted from 2\% agarose gels and purified using an AxyPrep DNA Gel Extraction kit (Axygen Biosciences, Union City, CA, USA) according to the manufacturer's instructions, and quantified using QuantiFluor-ST (Promega, Madison City, WI, USA). Purified amplicons were pooled in equimolar amounts and paired-end sequenced $(2 \times 300)$ on an Illumina MiSeq platform (Beijing Allwegene Technology Co., Ltd, China) according to standard protocols.

\section{Processing of Sequencing Data}

The extraction of high-quality sequences was performed with the QIIME package (Quantitative Insights Into Microbial Ecology) (version 1.2.1) (http://qiime.org/). Raw sequences were selected 
156

157

on the basis of sequence length, quality, primer, and tag. The raw sequences were selected and the low-quality sequences were removed as follows: (1) 300 bp reads were truncated at any site receiving a mean quality score of $<20$ over a $10 \mathrm{bp}$ sliding window, truncated reads that were shorter than 50 bp were discarded; (2) exact barcode matching, 2 nucleotide mismatch in primer matching, reads containing ambiguous characters were removed; (3) only sequences with an overlap longer than $10 \mathrm{bp}$ were assembled according to their overlap sequence. Reads that could not be assembled were discarded. Chimeric sequences were identified and removed based on the UCHIME algorithm (Edgar., 2011). The unique sequence set was classified into operational taxonomic units (OTUs) under the threshold of 97\% identity using UCLUST (Edgar., 2010) and then the taxonomic annotations were conducted for each OTU based on the Silva119 16S rRNA database using a confidence threshold of $90 \%$ (Quast et al., 2013). OTUs with less than five reads were removed to reduce the risk of artificially inflating richness due to sequencing errors (Chen et al., 2017).

\section{Data Analysis}

We performed separate one-way analysis of variance (ANOVA) with Tukey's test (equal variances) or Dunnett's T3 test (unequal variances) to determine the effects of wildfire of varying severity on soil physicochemical properties and the composition and diversity of the acidobacterial community in different soil layers $(0-10$ and 10-20 cm). The differences in the composition and diversity of the acidobacterial community between the topsoil and subsoil within different fire severities were also compared by independent-sample $t$-test. Pearson correlation analysis was used to determine relationships between the abundance of Acidobacteria subgroups and environmental variables. Differences were considered significant with a $P$ value of 0.05 as the threshold. All tests were carried out using SPSS 19.0 for Windows.

To correct for sampling efficiency, we used a randomly selected subset of 6,199 acidobacterial sequences (the minimum sample size among 24 samples) per sample for 
182

183

184

downstream analysis. Shannon-Wiener ( $\mathrm{H}^{\prime}$ Acidobacteria $)$ and Simpson ( $\mathrm{D}^{\prime}$ Acidobacteria $)$ indices of the acidobacterial community were calculated using the OTUs with $97 \%$ identity. Non-metric multidimensional scaling (NMDS) analysis based on Bray-Curtis and Weighted-Unifrac distance and permutational multivariate analysis of variance (PERMANOVA) were used to compare the composition of the acidobacterial community between different fire-damaged areas. Redundancy analysis (RDA) was carried out to assess the relationships between soil properties and acidobacterial community data (relative abundance of OTUs), and only environmental factors with variance inflation factor values of less than 20 were selected for the model (Xiang et al., 2014). A variance partitioning analysis (VPA) was further performed to quantify the effects of environmental factors on acidobacterial community structure. The above analyses were carried out with the Vegan package (Jari et al., 2018) in R (R Core Team, 2017).

\section{RESULTS}

\section{Soil Properties and Understory Vegetation}

Table 2 presents basic information on the physical and chemical properties of the soil after burning. One-way ANOVA showed that soil OM, TN, ammonium nitrogen $\left(\mathrm{NH}_{4}{ }^{+}-\mathrm{N}\right)$, and nitrate nitrogen $\left(\mathrm{NO}_{3}{ }^{-}-\mathrm{N}\right)$ in both soil layers significantly decreased with an increase in fire severity. However, soil $\mathrm{pH}$ showed the opposite trend in that it increased after burning. Interestingly, the patterns of change of SM in the topsoil and subsoil were inconsistent. The highest value of SM was observed in the topsoil of the high-severity fire area.

As shown in Fig. S2 and Table S2, the diversity of the understory vegetation was significantly changed after a high-severity wildfire. The highest value of Shannon-Wiener $\left(\mathrm{H}_{\text {Vegetation }}\right)$ and Simpson (D' $\left.{ }_{\text {Vegetation }}\right)$ indices and the lowest value of Pielou's evenness index $\left(\mathrm{J}^{\prime}\right.$ Vegetation $)$ were observed in the high-severity area compared with the other three types of plots 
$207(P<0.05)$. However, no significant differences were found among the moderate-severity, low208 severity, and unburnt areas.

209

Acidobacteria Community Composition and Structure

211

212

213

214

215

216

217

218

219

220

221

222

223

224

225

226

227

228

229

230

231

A total of 986,036 reads were detected using 24 samples through Illumina MiSeq sequencing. Of these reads, Acidobacteria is the most abundant phylum with a abundance of $31.77 \%$ (Fig S3). Each sample contained 6,199 to 27,585 acidobacterial reads (mean=13,053), with different phylotypes (OTUs) ranging from 173 to 370 (mean=309; total=7425). The Acidobacteria sequences obtained were further classified into 18 subgroups. Among them, subgroups 4, 6, 1, 3 and 2 were found to be dominant (abundance $>5 \%$ ) and common to the 24 libraries, which accounted for $31.55 \%, 30.84 \%, 17.42 \%, 6.02 \%$ and $5.81 \%$ of the total acidobacterial sequences across all soils, respectively (Fig. 2). The other 13 subgroups (subgroups 5, 7, 10-13, 15, 17, 18, $20,22,25,26)$ were also found, but at a relatively low abundance $(<5 \%)$.

The acidobacterial diversity patterns along a fire severity gradient were analyzed by the number of reads, number of OTUs, Shannon index and Simpson index. We found no significant differences in the same soil layer among different fire severities by one-way ANOVA (Fig. 3; Table S3). However, independent-sample $t$-tests showed a significantly lower number of reads, but higher Shannon and Simpson indices in the topsoil of the high-severity fire area compared with the subsoil $(P<0.05)$ (Fig. 3; Table S4).

NMDS analysis was used to distinguish differences in the acidobacterial community structure between the two soil layers. Figure S4 shows that the acidobacterial community structure of topsoil and subsoil is clearly divided into two parts. The PERMANOVA further confirmed that the acidobacterial community structure in the topsoil was significantly different from that in the subsoil $\left(\mathrm{R}^{2}=0.1317, P=0.048\right)$. 
232

233

234

235

236

237

238

239

240

241

242

243

244

245

246

247

248

249

250

251

252

253

254

255

256

257

258

\section{Relationship Between the Acidobacterial Community Structure and Environmental} Factors

RDA was used to examine the relationships between the soil acidobacterial community structure and environmental factors. Based on the test of the variance inflation factor, soil $\mathrm{TN}, \mathrm{NH}_{4}{ }^{+}-\mathrm{N}$, $\mathrm{pH}$, the diversity of understory vegetation ( $\mathrm{H}^{\prime}$ Vegetation, $\mathrm{D}^{\prime}$ Vegetation and $\mathrm{J}$ 'Vegetation), plant $\mathrm{DBH}$, plant height and canopy density were selected for the RDA model of topsoil; and soil $\mathrm{OM}, \mathrm{NO}_{3}{ }^{-}-\mathrm{N}$, $\mathrm{SM}, \mathrm{pH}$, the diversity of understory vegetation ( $\mathrm{H}^{\prime}$ Vegetation, $\mathrm{D}^{\prime}$ Vegetation and $\mathrm{J}_{\text {'Vegetation }}$ ), plant $\mathrm{DBH}$ and plant height were adopted for the RDA model of subsoil. Permutation test results indicated that the effects of soil $\mathrm{pH}, \mathrm{TN}, \mathrm{NH}_{4}^{+}-\mathrm{N}, \mathrm{H}^{\prime}$ Vegetation and canopy density on the soil acidobacterial community structure reached a significant level in topsoil $(P<0.05)$ (Fig. 4a). Meanwhile, soil pH and OM were found to be significant factors that influenced soil acidobacterial community structure in the subsoil (Fig. 4c).

On the basis of RDA, we classified the environmental factors selected by the model into three parts. TN, $\mathrm{NH}_{4}{ }^{+}-\mathrm{N}, \mathrm{pH}, \mathrm{OM}, \mathrm{NO}_{3}{ }^{-}-\mathrm{N}$ and $\mathrm{SM}$ were classified as edaphic factors. $\mathrm{H}^{\prime}$ Vegetation, D' Vegetation and J' Vegetation were classified as understory vegetation diversity factors. Canopy density, DBH, and plant height were classified as plant community structure factors. VPA was conducted to assess the relative contributions of edaphic factors, understory vegetation diversity, and plant community structure to the acidobacterial community structure. In the topsoil, the combination of these variables explained $23.6 \%$ of the observed variation in soil acidobacterial community structure. Edaphic factors explained the largest fraction of the variation (15.6\%), with an independent effect of $9.8 \%$. Understory vegetation diversity and plant community structure independently explained $5.8 \%$ and $1.2 \%$ of the variation, respectively (Fig. $4 \mathrm{~b})$. In the subsoil, $69.4 \%$ of the variation was explained by the combination of the variables, with edaphic factors accounting for the largest fraction of the variation (56.3\%) (Fig. 4d). The results showed that edaphic factors were the main factors affecting the acidobacterial community structure both in topsoil and subsoil. However, a large number of the factors involved especially in the topsoil, are still unknown. 
259

260

261

262

263

264

265

266

267

268

269

270

271

272

273

274

275

276

277

278

279

280

281

282

283

284

Consistent with the results of the VPA, we also found different relationships between the relative abundance of Acidobacteria subgroups and soil factors. For example, in the topsoil, the relative abundance of Acidobacteria subgroup 1 was significantly positively correlated with $\mathrm{NH}_{4}{ }^{+}-\mathrm{N}(\mathrm{r}=0.698, \mathrm{p}<0.05)$, while the relative abundance of subgroup 7 was significantly negatively related to $\mathrm{NH}_{4}{ }^{+}-\mathrm{N}(\mathrm{r}=-0.655, \mathrm{p}<0.05)$. In the subsoil, the relative abundance of Acidobacteria subgroups $1(\mathrm{r}=0.849, \mathrm{p}<0.01)$ and $3(\mathrm{r}=0.607, \mathrm{p}<0.05)$ were found to be significantly positively correlated with OM. By contrast, the relative abundance of subgroups 4 $(\mathrm{r}=-0.630, \mathrm{p}<0.05), 10(\mathrm{r}=-0.577, \mathrm{p}<0.05), 18(\mathrm{r}=-0.651, \mathrm{p}<0.05)$ and $20(\mathrm{r}=-0.582, \mathrm{p}<0.05)$ showed an opposite relationship with OM. We also found that not all Acidobacteria subgroups showed a consistent relationship with soil $\mathrm{pH}$ in the two soil layers. Except for Acidobacteria subgroups 3 and 4, the relationships between other subgroups and soil $\mathrm{pH}$ were found to be consistent in the two soil layers. However, the dominant subgroups 3 and 4 showed a negative relationship in the topsoil ( relationship in the subsoil (subgroup3: $r=0.025$; subgroup4: $r=0.803$ ) (Table S5; Table S6).

\section{DISCUSSION}

Soil Acidobacteria are widespread and abundant in natural ecosystems (Mbuthia et al., 2015; Liu et al., 2016), and have been analyzed in different environments, such as in wastewater treatment processes (Crocetti et al., 2002), hot springs (Hobel et al., 2005), sand dunes (Smith et al., 2004 ), an acidic sphagnum peat bog (Dedysh et al., 2006), Amazon forest soils (Navarrete et al., 2015) and Chinese fir plantations (Liu et al., 2017). However, the responses of the acidobacterial community to a fire disturbance are still limited. In this study, we analyzed the variation of Acidobacteria in a P. tabulaeformis forest after a wildfire. The results of Illumina MiSeq sequencing showed that $31.77 \%$ of the reads belonged to Acidobacteria across all the soil samples. Overall, 18 different Acidobacteria subgroups were detected in this study, with subgroups 4, 6, 1, 3 and 2 found to be dominant. This finding is similar to that of Zhang et al. 
285

286

287

288

289

290

291

292

293

294

295

296

297

298

299

300

301

302

303

304

305

306

307

308

309

310

311

(2014), who also found 19 known subdivisions in Shennongjia Mountain, Central China, of which subdivisions $6,1,2,3,4$ showed relative high abundance.

Fire has a strong effect on the diversity of the soil microbial community. A decrease of soil bacterial diversity can be observed after burning, especially after a high-severity fire (Ferrenberg et al., 2013; Xiang et al., 2014). Mabuhay et al. (2006) reported that the burnt areas still showed very low microbial community diversity even 1 year after a fire. Xiang et al. (2014) observed that the diversity of the bacterial community returned to match that of the unburnt controls 11 years after the fire. Microbial diversity tends to recover gradually over a long time (Shen et al., 2016). However, we found no significant differences of the acidobacterial $\alpha-$ diversity in the topsoil or subsoil (Fig. 3). We speculated that the soil acidobacterial community might recover in a much faster time. Interestingly, although the number of reads in the topsoil was significantly lower than that in the subsoil, a significantly higher acidobacterial $\alpha-$ diversity (i.e. Shannon and Simpson indices) was observed in the topsoil than in the subsoil of high severity plots (Fig. 3). This phenomenon may be due to the edaphic and vegetable heterogeneity caused by fire, enabling bacterial diversity to be maintained and even improved with the change of microbial competition for resources (Chesson, 2000; Otsuka et al., 2008; Artz et al., 2009).

Numerous studies have demonstrated that soil microbial communities are closely related to aboveground vegetation and soil properties (Bardgett 2005; Chu et al., 2016). Among them, Acidobacteria were found to play a role in promoting soil carbon cycling, as it can degrade complex plant derived polysaccharides such as cellulose and lignin (Huang et al., 2015). Soil pH has often been reported as a dominant factor in shifting acidobacterial communities (Xiong et al., 2012; Xiang et al., 2014; Chu et al., 2016). This conclusion has also been confirmed in this study, where we found that soil $\mathrm{pH}$ was a key factor both in the topsoil and subsoil (Fig. 4a; Fig. 4c). Previous studies have shown that different subgroups presented inconsistent correlations with respect to soil $\mathrm{pH}$. For example, Turlapati et al. (2013) reported that subgroups 1, 2, 3, 12, and 13 were positively correlated with soil $\mathrm{pH}$, but subgroups $4,6,7,10,11,16,17,18,22$, and 25 
312

313

314

315

316

317

318

319

320

321

322

323

324

325

326

327

328

329

330

331

332

333

334

335

336

337

338

showed a negative correlation. However, an opposite relationship was reported in the review article by Kielak and colleagues (Kielak et al., 2016), who showed that $\mathrm{pH}$ had a negative relationship with the abundance of subgroups 1,2,3,12,13, and 15, but a positive correlation with subgroups $4,6,7,10,11,16,17,18,22$, and 25 . In this study, we found not only that the relationships between Acidobacteria subgroups and soil $\mathrm{pH}$ were inconsistent in the same soil layer, but also that certain subgroups had different relationships with soil $\mathrm{pH}$ in different soil layers. For instance, the dominant subgroups 3 and 4 showed a negative relationship with soil $\mathrm{pH}$ in the topsoil, but a positive relationship in the subsoil (Table S5; Table S6). We hypothesized that the varied responses of the Acidobacteria subgroups to soil $\mathrm{pH}$ represented the key determinant of the different relationships between Acidobacteria and soil pH. However, the relationship between Acidobacteria subgroups and soil properties with the change of soil depth still needs further study.

Soil nitrogen and OM were also found to be important parameters in driving the acidobacterial community structures in the topsoil and subsoil, respectively (Fig. 4a; Fig. 4c). Ward et al. (2009) reported that Acidobacteria played an important role in nitrogen cycling, and subgroup 1 had related correlations with nitrate and nitrite. In this study, we also found a significant relationship between subgroup 1 and $\mathrm{NH}_{4}{ }^{+}-\mathrm{N}$ in the topsoil (Table S5). Acidobacteria are usually considered to be oligotrophic (Fierer et al., 2007; Jones et al., 2009). Navarrete et al. (2015) found a significant positive relationship between the abundance of Acidobacteria and soil OM. Liu et al. (2016) also observed a larger abundance of Acidobacteria in high organic carbon content soils than in low carbon content soils in the black zone of northeast China. It has been pointed out that not all subgroups or OTUs of this phylum would be oligotrophic (Fierer et al., 2007; Chu et al., 2016). In this study, subgroups 4, 10, 18, and 20 were found to be significantly negatively related to soil OM in the subsoil which suggesting oligotrophy(Table S6). However, a significant positive relationship was also detected between the dominant subgroups 1 and 3 and soil OM in this soil layer (Table S6). Kielak et al. (2016) proposed that not all Acidobacteria possess the same ecological strategy, with a high variation of physiological characteristics within 
339

this phylum.

Extensive studies have suggested that there are strong interrelationships between aboveground vegetation and soil microbial communities (Hart et al., 2005; Nielsen et al., 2010; Dangi et al., 2010). A larger microbial biomass was found in a forest of greater aboveground diversity than in a homogeneous plant cover environment (Fioretto et al., 2009). Hart et al. (2005) considered that changes in vegetation community structure in the years following a fire might have a greater effect on soil microbial communities than the direct influence of the fire disturbance itself. For example, the soil nutrient and carbon content could be influenced by the inputs of litter (leaves, stems, roots) and exudate from newly established plants after burning (Knelman et al., 2015). In this study, the Shannon diversity and canopy density of aboveground vegetation were found to have significant effects on the acidobacterial community structure in the topsoil (Fig. 4a). We hypothesize that an important reason for the higher diversity of the acidobacterial community in the topsoil of the high-severity area is the increase in aboveground vegetation diversity (Han et al., 2007; Zhang et al., 2014) and we also found $\mathrm{H}^{\prime}$ Vegetation play an important in driving the change of acidobacterial community in this soil layer (Fig. 4a). Further, changes in plant community structure, such as the decline in canopy density, increase the light availability and soil temperature in the forest, which are beneficial for the bacterial communities (Arunachalam \& Arunachalam, 2000; Bolat, 2014). However, the result of the VPA showed that a large amount of the variation remained unexplained in this study, especially in the topsoil (Fig. 4b; Fig. 4d). Other studies show that climate change (Maestre et al., 2015), soil metal elements (Navarrete et al., 2015), and soil enzyme activities (Zhang et al., 2014) also play important roles in determining microbial community structures. Accordingly, further comprehensive studies of Acidobacteria are necessary.

\section{CONCLUSION}

In summary, this study conducted the response of soil Acidobacteria to fire disturbance by the Illumina MiSeq sequencing technique. We found no significant differences in acidobacterial 
365

366

367

368

369

370

371

372

373

374

375

376

377

378

379

380

381

382

383

384

385

386

387 $\alpha$-diversity in the topsoil or subsoil across different fire severities. However, the community structure of soil Acidobacteria in the topsoil was significantly different from that in the subsoil.

We found that soil $\mathrm{pH}$ was a key factor in driving acidobacterial community structure in both soil layers while several other factors (e.g. total nitrogen, $\mathrm{NH} 4+-\mathrm{N}, \mathrm{H}$ 'Vegetation and organic matter) also have an important effect. The Acidobacteria subgroups were found to show different variations after a wildfire. The differential responses of the Acidobacteria subgroups to specific environmental factors can help to reveal what drives their population changes in forest soils recently suffering a fire disturbance and open the possibilities to explore acidobacterial subgroups as bioindicators for ecosystem restoration in Pinus tabulaeformis stands.

\section{REFERENCES}

Artz, R. R. E., Reid, E., Anderson, I. C., Campbell, C. D., and Cairney, J. W. G. (2009). Long term repeated prescribed burning increases evenness in the basidiomycete laccase gene pool in forest soils. FEMS Microbiol Ecol. 67, 397-410. DOI: 10.1111/j.1574-6941.2009.00650.x.

Arunachalam, A., and Arunachalam, K. (2000). Influence of gap size and soil properties on microbial biomass in a subtropical humid forest of north-east India. Plant Soil. 223, 187-195. DOI: 10.1023/A:100482822.

Bardgett, R.D. (2005). The Biology of Soil: A Community and Ecosystem Approach. Oxford University Press, New York, pp. 57-85.

Barns, S. M., Cain, E. C., Sommerville, L., and Kuske, C. R. (2007). Acidobacteria phylum sequences in uranium-contaminated subsurface sediments greatly expand the known diversity within the phylum. Appl. Environ. Microbiol. 73, 3113-3116. DOI:10.1128/AEM.02012-06.

Best, E. X. (1976). An automated method for determining nitrate-N in soil extracts. Queensland Agricultural Journal. 33, 161-165.

Bolat, I. (2014). The effect of thinning on microbial biomass $\mathrm{C}, \mathrm{N}$ and basal respiration in black pine forest soils in Mudurnu, Turkey. Eur. J. For. Res. 133, 131-139. DOI: 10.1007/s10342-013-0752-8. 
390

391

392

393

394

395

396

Chen, Q., Zhao, Y. S., Xin, Y., and Han, X. C. (2013). Litter and soil water-holding capacity of burned area in northern slope of the great khingan after vegetation restoration. Chinese Journal of Soil Science. 44, 308-313. DOI: $10.19336 / j . c n k i . t r t b .2013 .02 .008$.

Chen, Y. L., Xu, T. L., Veresoglou, S. D., Hu, H. W., Hao, Z. P., Hu, Y. J., et al. (2017). Plant diversity represents the prevalent determinant of soil fungal community structure across temperate grasslands in northern China. Soil Biol. Biochem. 110, 12-21. DOI: 10.1016/j.soilbio.2017.02.015.

Chesson, P. Mechanisms of maintenance of species diversity. (2000). Annu. Rev. Ecol. Syst. 31, 343-366.

Chu, H., Sun, H., Tripathi, B. M., Adams, J. M., Huang, R., Zhang, Y., et al. (2016). Bacteria community dissimilarity between the surface and subsurface soils equals horizontal differences over several kilometers in the western Tibetan Plateau. Environ. Microbiol. DOI: 10.1111/1462-2920.13236.

Crocetti, G. R., Banfield, J. F., Keller, J., Bond, P. L., and Blackall, L. L. (2002). Glycogen-accumulating organisms in laboratory-scale and full-scale wastewater treatment processes. Microbiology. 148, 3353-3364. DOI:10.1099/00221287-148-11-3353.

Crooke, W. M., and Simpson, W. E. (1971). Determination of ammonium in Kjeldahl extracts of crops by an automated procedure. Journal of the Science of Food \& Agriculture. 22, 9-10. DOI:10.1016/S0039-9140(97)00091-X.

Dangi, S. R., Stahl, P. D., Pendall, E., Cleary, M. B., and Buyer., J. S. (2010). Recovery of soil microbial community structure after fire in a sagebrush-grassland ecosystem. Land Degradation \& Development. 21, 423-432. DOI: 10.1002/ldr.975.

de Castro, V. H. L., Schroeder, L. F., Quirino, B. F., Kruger, R. H., and Barreto, C. C. (2013). Acidobacteria from oligotrophic soil from the Cerrado can grow in a wide range of carbon source concentrations. Can. J. Microbiol. 59, 746-753. DOI: 10.1139/cjm-2013-0331.

Dedysh, S. N., Pankratov, T. A., Belova, S. E., Kulichevskaya, I. S., and Liesack, W. (2006). Phylogenetic analysis and in situ identification of bacteria community composition in an acidic sphagnum peat bog. Appl. Environ. Microbiol. 72, 2110-2117. DOI: 10.1128/AEM.72.3.2110- 
Edgar, R. C. (2010). Search and clustering orders of magnitude faster than BLAST. Bioinformatics. 26, 2460-2461. DOI: 10.1093/bioinformatics/btq461.

Edgar, R. C., Haas, B. J., Clemente, J. C., Quince, C. and Knight, R. (2011). Uchime improves sensitivity and speed of chimera detection. Bioinformatics, 27(16), 2194. DOI: 10.1093/bioinformatics/btr381.

Eichorst, S. A., Kuske, C. R. and Schmidt, T. M. (2011). Influence of plant polymers on the distribution and cultivation of bacteria in the phylum acidobacteria. Applied and Environmental Microbiology, 77(2), 586-596. DOI: 10.1128/AEM.01080-10.

Ferrenberg, S., O'Neill, S. P., Knelman, J. E., Todd, B., Duggan, S., Bradley, D., et al. (2013). Changes in assembly processes in soil bacterial communities following a wildfire disturbance. ISME J. 7, 11021111. DOI: $10.1038 /$ ismej.2013.11.

Fierer, N., Bradford, M. A., and Jackson, R. B. (2007). Toward an ecological classification of soil bacteria. Ecology. 88, 1354-1364. DOI:10.1890/05-1839.

Fioretto, A., Papa, S., Pellegrino, A., and Ferriguo, A. (2009). Microbial activities in soils of a Mediterranean ecosystem in different successional studies. Soil Biol. Biochem. 41, 2061-2068. DOI: 10.1016/j.soilbio.2009.07.010.

Griffiths, R. I., Thomson, B. C., James, P., Bell, T., Bailey, M., Whiteley, A. S. (2011). The bacterial biogeography of British soils. Environ. Microbiol. 13, 1642-1654. DOI: 10.1111/j.14622920.2011.02480.x.

Han, X. M., Wang, R. Q., Liu, J., Wang, M. C., Zhou, J., and Guo, E. H. (2007). Effects of vegetation type on soil microbial community structure and catabolic diversity assessed by polyphasic methods in North China. Journal of Environmental Sciences. 19, 1228-1234. DOI: 10.1016/S10010742(07)60200-9.

Hart, S. C., Deluca, T. H., Newman, G. S., MacKenzie, M. D., and Boyle, S.I. (2005). Post-fire vegetative 
439

440

441

442

443

444

445

446

447

448

449

450

451

452

453

454

455

456

457

458

459

460

461

462

463

dynamics as drivers of microbial community structure and function in forest soils. Forest Ecology \& Management. 220, 166-184. DOI: 10.1016/j.foreco.2005.08.012.

Hobel, C. F. V., Marteinsson, V. T., Hreggvidsson, G. O., and Kristjansson, J. K. (2005). Investigation of the microbial ecology of intertidal hot springs by using diversity analysis of 16S rRNA and chitinase genes. Appl. Environ. Microbiol. 71, 2771-2776. DOI: 10.1128/AEM.71.5.2771-2776.2005.

Huang, X., Liu, L., Wen, T., Zhu, R., Zhang, J., and Cai, Z. (2015). Illumina MiSeq investigations on the changes of microbial community in the Fusarium oxysporum f.sp. Cubense infected soil during and after reductive soil disinfestation. Microbiol. Res. 181, 33-42. DOI:10.1016/j.micres. 2015. 08.004.

Jari, O. F., Guillaume, B., Michael, F., Roeland, K., Pierre, L., Dan, M., et al. (2018).vegan: Community Ecology Package. R package version 2.5-3. https:/CRAN.R-project.org/package=vegan.

Jones, R. T., Robeson, M. S., Lauber, C. L., Hamady, M., Knight, R., and Fierer, N. (2009). A comprehensive survey of soil acidobacterial diversity using pyrosequencing and clone library analyses. ISME J. 3, 442-453. DOI:10.1038/ ismej.2008.127.

Kielak, A. M., Barreto, C. C., Kowalchuk, G. A., Van, V. J. A., and Kuramae, E. E. (2016) The Ecology of Acidobacteria: Moving beyond Genes and Genomes. Front. Microbiol. 7, 744. DOI: 10.3389/fmicb.2016.00744.

Knelman, J. E., Graham, E. B., Trahan, N. A., Schmidt, S. K., and Nemergut, D.R. (2015). Fire severity shapes plant colonization effects on bacterial community structure, microbial biomass, and soil enzyme activity in secondary succession of a burned forest. Soil Biol. Biochem. 90, 161-168. DOI: 10.1016/j.soilbio.2015.08.004.

Kristal, M. G., and Kathleenk, T. (2010). Microbial communities and their relevance for ecosystem models: Decomposition as a case study. Soil Biol. Biochem. 42, 529-535. DOI: 10.1016/j.soilbio.2009.11.016.

Lehmann, C. E., Anderson, T. M., Sankaran, M., Higgins, S. I., Archibald, S., Hoffmann WA., et al. (2014). Savanna Vegetation-Fire-Climate Relationships Differ Among Continents. Science. 343, 548. 
DOI: $10.1126 /$ science. 1247355 .

465

466

467

468

469

470
Li, T. Y., Kang, F. F., Han, H. R., Gao, J., and Song, X. S. (2015). Characteristics of Microbial Carbolic Metabolism in Soils of Pinus tabulaeformis in Liaohe River of Northern Hebei. Soil. 47, 500-557. DOI: $10.13758 /$ j.cnki.tr.2015.03.019.

Li, W. K., Niu, S. K., Liu, X. D., et al. (2019). Short-term response of the soil bacterial community to differing wildfire severity in Pinus tabulaeformis stands. Sci. Rep. 9, 1148. DOI: 10.1038/s41598019-38541-7.

Liu, C. X., Dong, Y. H., Hou, L. Y., Deng, N., and Jiao, R. Z. (2017). Acidobacteria Community Responses to Nitrogen Dose and Form in Chinese Fir Plantations in Southern China. Curr Microbiol. 74, 396. DOI: 10.1007/s00284-016-1192-8.

Liu, J. J., Sui, Y. Y., Yu, Z. H., Yao, Q., Shi, Y., Chu, H. Y., et al. (2016). Diversity and distribution patterns of acidobacterial communities in the black soil zone of northeast China. Soil Biol. Biochem. 95, 212-222. DOI: 10.1016/j.soilbio.2015.12.021.

Liu R L., Wang L., Liu Q F., Wang Z X., Li Z Z., Fang J S., Zhang L and Luo M. (2018). Depth-resolved distribution of particle-attached and free-living bacterial communities in the water column of the new britain trench. Frontiers in Microbiology, 9, 625- DOI: 10.3389/fmicb.2018.00625.

Maestre, F. T., Delgado-Baquerizo, M., Jeffries, T. C., Eldridge, D. J., Ochoa, V., Gozalo, B., et al. (2015). Increasing aridity reduces soil microbial diversity and abundance in global drylands. $P A N S$. 112, 15684-15689. DOI: 10.1073/pnas.1516684112.

Mbuthia, L. W., Acosta-Martínez, V., Debryun, J., Schaeffer, S., Tyler, D., ODOI, E., et al. (2015). Long term tillage, cover crop, and fertilization effects on microbial community structure, activity: Implications for soil quality. Soil Biol. Biochem. 89, 24-34. DOI:10.1016/j.soilbio.2015.06.016.

Mikita-Barbato, R. A., Kelly, J. J., and Tate, R. L. (2015). Wildfire effects on the properties and microbial community structure of organic horizon soils in the New Jersey Pinelands. Soil Biol. Biochem. 86, 67-76. DOI: 10.1016/j.soilbio.2015.03.021. 
489

490

491

492

493

494

495

496

497

498

499

500

501

502

503

504

505

506

507

508

509

510

511

512

513

Naether, A., Foesel, B. U., Naegele, V., Wüst, P. K., Weinert, J., Bonkowski, M., et al. (2012). Environmental factors affect acidobacterial communities below the subgroup level in grassland and forest soils. Applied and Environmental Microbiology. 78, 7398-7406. DOI: 10.1128/AEM.0132512.

Navarrete, A. A., Kuramae, E. E., de Hollander, M., Pijl, A. S., Veen, J. A., and Tsai, S. M. (2013). Acidobacterial community responses to agricultural management of soybean in Amazon forest soils. FEMS Microbiol Ecology. 83, 607-621. DOI:10.1111/1574-6941.12018.

Navarrete, A. A., Venturini, A. M., Meyer, K. M., Klein, A. M., Tiedje, J. M., Bohannan, B. J. M., et al. (2015). Differential Response of Acidobacteria Subgroups to Forest-to-Pasture Conversion and Their Biogeographic Patterns in the Western Brazilian Amazon. Front. Microbiol. 6,1443. DOI: 10.3389/fmicb.2015.01443.

Nielsen, U. N., Osler, G. H. R., Campbell, C. D., Burslem, D. F. R. P., and van der Wal, R. (2010). The influence of vegetation type, soil properties and precipitation on the composition of soil mite and microbial communities at the landscape scale. Journal of Biogeography. 37, 1317-1328. DOI: $10.1111 / j .1365-2699.2010 .02281 . x$.

Niu, S. K. (2011). Fire behavior and fuel spacial continuity of major forest types in the mountainous area, Beijing. [dissertation]. [Beijing]: Beijing Forestry University

Otsuka, S., Sudiana, I., Komori, A., Isobe, K., Deguchi, S., Nishiyama, M., et al. (2008). Community Structure of Soil Bacteria in a Tropical Rainforest Several Years After Fire. Microbes \& Environments. 23, 49-56. DOI: 10.1264/jsme2.23.49.

Pressler Y , Moore J C , Cotrufo M F . (2018). Belowground community responses to fire: meta-analysis reveals contrasting responses of soil microorganisms and mesofauna. Oikos. DOI:10.1111/oik.05738.

Quast, C., Pruesse, E., Yilmaz, P., Gerken, J., Schweer, T., Yarza, P., Peplies, J and Glöckner, F. O. (2013). The SILVA ribosomal RNA gene database project: improved data processing and web-based tools. Nucl. Acids Res. 41 (D1): D590-D596. 
514

515

516

517

518

519

520

521

522

523

524

525

526

527

528

529

530

531

532

533

534

535

536

537

538

R Core Team (2017). R: A language and environment for statistical computing. R Foundation for Statistical Computing, Vienna, Austria. URL https://www.R-project.org/.

Shen, J. P., Chen, C. R., and Lewis, T. (2016). Long term repeated fire disturbance alters soil bacterial diversity but not the abundance in an Australian wet sclerophyll forest. Sci. Rep. 6, 19639. DOI: $10.1038 /$ srep 19639.

Smith, S. M., Abed, R. M. M., and Garcia-Pichel, F. (2004). Biological soil crusts of sand dunes in Cape Cod National Seashore, Massachusetts, USA. Microb. Ecol. 48, 200-208. DOI: 10.1007/s00248-0040254-9.

Sul, W. J., Asuming-Brempong, S., Wang, Q., Tourlousse, D. M., Penton, C. R., Deng, Y., et al. (2013). Tropical agricultural land management influences on soil microbial communities through its effect on soil organic carbon. Soil Biology and Biochemistry, 65, 33-38. DOI: 10.1016/j.soilbio.2013.05.007.

Sun, H., Santalahti, M., Pumpanen, J., Köster, K., Berninger, F., Raffaello, T., et al. (2016). Bacterial community structure and function shift across a northern boreal forest fire chronosequence. Sci. Rep. 6, 32411. DOI: $10.1038 / \mathrm{srep} 32411$.

Turlapati, S. A., Minocha, R., Bhiravarasa, P. S., Tisa, L. S., Thomas, W. K., and Minocha, S. C. (2013). Chronic N-amended soils exhibit an altered bacterial community structure in Harvard Forest, MA, USA. FEMS Microbiol Ecol. 83, 478-493. DOI:10.1111/1574-6941.12009.

Walkley, A., and Black, I. A. (1934). An examination of Degtjareff method for determining soil organic matter and a proposed modification of the chromic acid titration method. Soil Science. 37, 29-38.

Wang, J., and Yan, Q. L. (2017). Effects of disturbances on animal-mediated seed dispersal effectiveness of forest plants: A review. Chinese Journal of Applied Ecology. 28, 1716-1726. DOI:10.13287/j.1001-9332.201705.033.

Ward, N. L., Challacombe, J. F., Janssen, P. H., Henrissat, B., Coutinho, P. M., Wu, M., Xie, G., Haft, D. H., Sait, M., Badger, J., Barabote, R. D., Bradley, B., Brettin, T. S., Brinkac, L. M., Bruce, D.,

Peer) reviewing PDF | (2018:10:31972:2:0:NEW 2 Oct 2019) 
Creasy, T., Daugherty, S. C., Davidsen, T. M., DeBoy, R. T., Detter, J. C., Dodson, R. J., Durkin, A. S., Ganapathy, A., Gwinn-Giglio, M., Han, C. S., Khouri, H., Kiss, H., Kothari, S. P., Madupu, R., Nelson, K. E., Nelson, W. C., Paulsen, I., Penn, K., Ren, Q., Rosovitz, M. J., Selengut, J. D., Shrivastava, S., Sullivan, S. A., Tapia, R., Thompson, L. S., Watkins, K. L., Yang, Q., Yu, C., Zafar, N., Zhou, L., Kuske, C. R. (2009). Three genomes from the phylum Acidobacteria provide insight into the lifestyles of these microorganisms in soils. Appl Environ Microbiol. 75, 2046-2056. DOI:10.1128/aem.02294-08.

Weber, C. F., Lockhart, J. S., Charaska, E., Aho, K., and Lohse, K. A. (2014). Bacterial composition of soils in ponderosa pine and mixed conifer forests exposed to different wildfire burn severity. Soil Biol. Biochem. 69, 242-250. DOI: 10.1016/j.soilbio.2013.11.010.

Xiang, X. J., Shi, Y., Yang, J., Kong, J. J., Lin, X. G., Zhang, H. Y., Zeng, J., Chu, H. Y. (2014). Rapid recovery of soil bacterial communities after wildfire in a Chinese boreal forest. Sci. Rep. 4, 3829. DOI: $10.1038 /$ srep03829.

Xiong, J. B., Liu, Y. Q., Lin, X. G., Zhang, H. Y., Zeng, J., Hou, J. Z., Yang, Y. P., Yao, T. D., Knight, R., Chu, H. Y. (2012). Geographic distance and pH drive bacterial distribution in alkaline lake sediments across Tibetan Plateau. Environmental Microbiology. 14, 2457-2466. DOI: 10.1111/j.1462-2920.2012.02799.x.

Xue, L., Li, Q. J., and Chen, H. (2014). Effects of a Wildfire on Selected Physical, Chemical and Biochemical Soil Properties in a Pinus massoniana Forest in South China. Forests. 5, 2947-2966 (2014). DOI: 10.3390/f5122947.

Yu, Y., Wang, H., Liu, J., Wang, Q., Shen, T. L., Guo, W. H., et al. (2012). Shifts in microbial community function and structure along the successional gradient of coastal wetlands in Yellow River Estuary. European Journal of Soil Biology. 49, 12-21. DOI: 10.1016/j.ejsobi.2011.08.006.

Zhang, Y. G., Cong, J., Lu, H., Li, G. L., Qu, Y. Y., and Su, X. J. (2014). Community structure and elevational diversity patterns of soil Acidobacteria. Journal of Environmental Sciences. 26, 1717 - 
565 Zheng Q., Cui, X. Y., and Di, X. Y. (2012). Effects of Different Forest Fire Intensities on Microbial Community Functional Diversity in Forest Soil in Daxing'anling. Scientia Silvae Sinicae. 48, 95-100. fuel management in Pinus tabulaeformis forests in the Beijing West Mountain Area. Acta 
Figure 1

Photographs depicting different fire severity areas.

(a) high severity area (b) moderate severity area (c) low severity area (d) unburnt control area. 

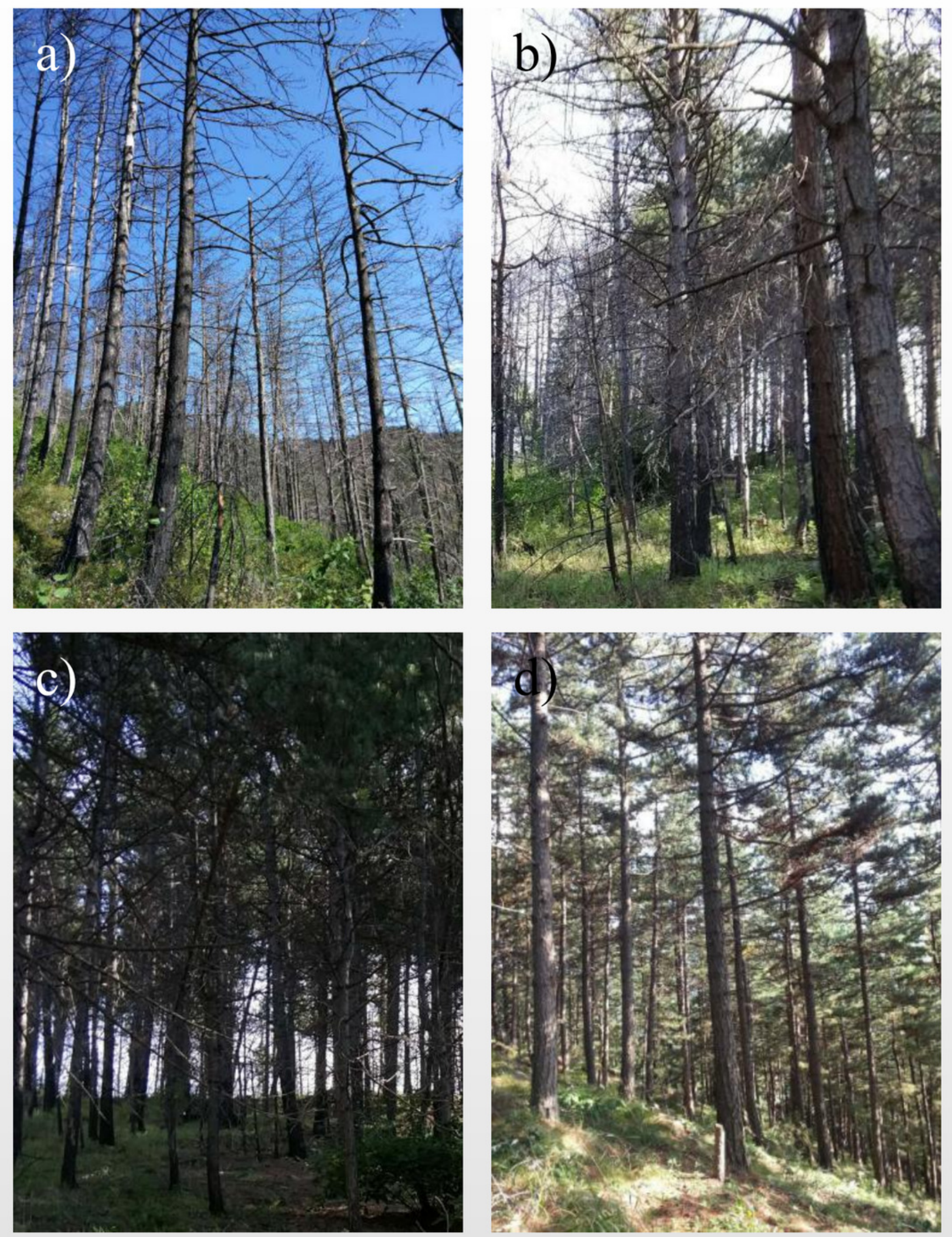


\section{Figure 2}

Relative abundance of dominant acidobacterial subgroups in areas affected by differing fire severity.

$H$, high severity; $M$, moderate severity; $L$, low severity; $C$, unburnt control; 10 , topsoil (0-10 $\mathrm{cm}) ; 20$, subsoil $(10-20 \mathrm{~cm})$.

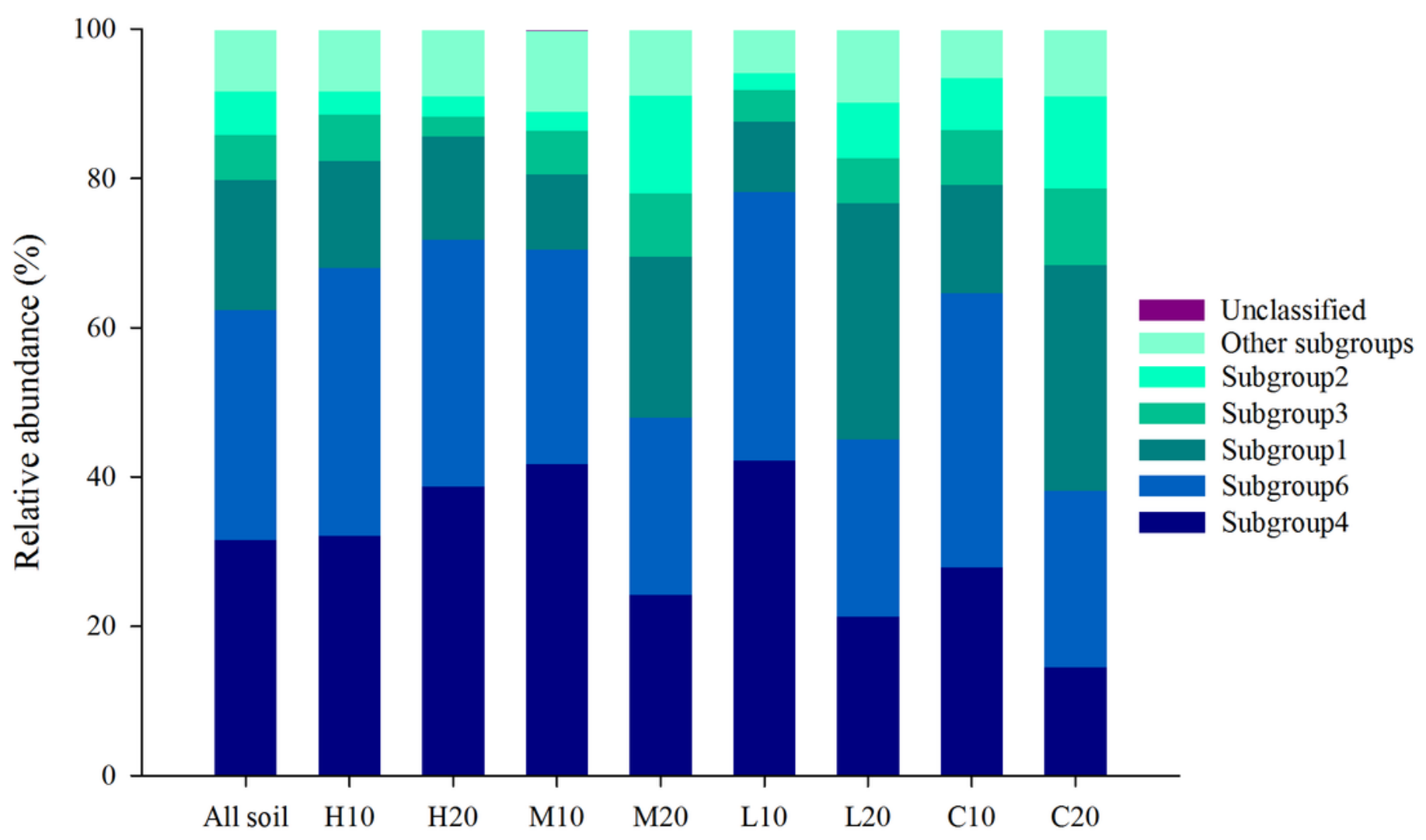




\section{Figure 3}

Sequencing results and acidobacterial $\alpha$-diversity in different fire severity areas.

Different lowercase letters indicate a significant difference in different soil layers of the same fire severity plots at the $P<0.05$ level; different capital letters represent a significant difference in the same soil layer of different fire severity plots at the $P<0.05$ level. $\mathrm{H}$, high severity; M, moderate severity; L, low severity; C, unburnt control; 10, topsoil $(0-10 \mathrm{~cm}) ; 20$, subsoil $(10-20 \mathrm{~cm})$. 

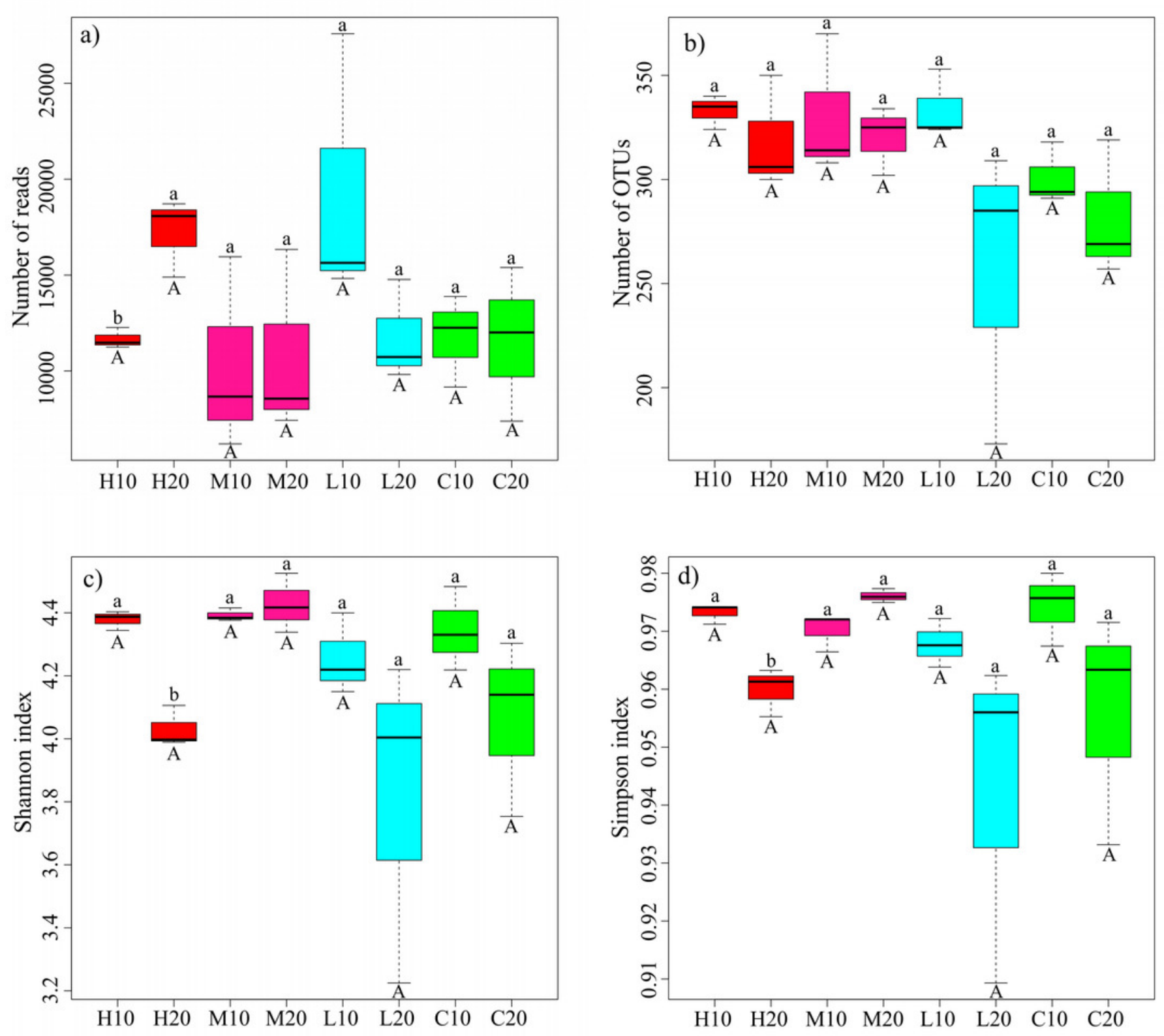


\section{Figure 4}

Redundancy analysis (RDA) and variance partitioning analysis (VPA) show the relationship between acidobacterial community and environmental factors in the topsoil $(a \& b)$ and subsoil (c\&d).

Circle diagrams indicate the independent and shared variance explained by environmental factors in the topsoil (b) and subsoil (d) respectively.l: edaphic factors; II: understory vegetation diversity factors; III: plant community structure factors. $H$, high severity; $M$, moderate severity; L, low severity; $C$, unburnt control; 10 , topsoil $(0-10 \mathrm{~cm}) ; 20$, subsoil $(10-20 \mathrm{~cm})$. 

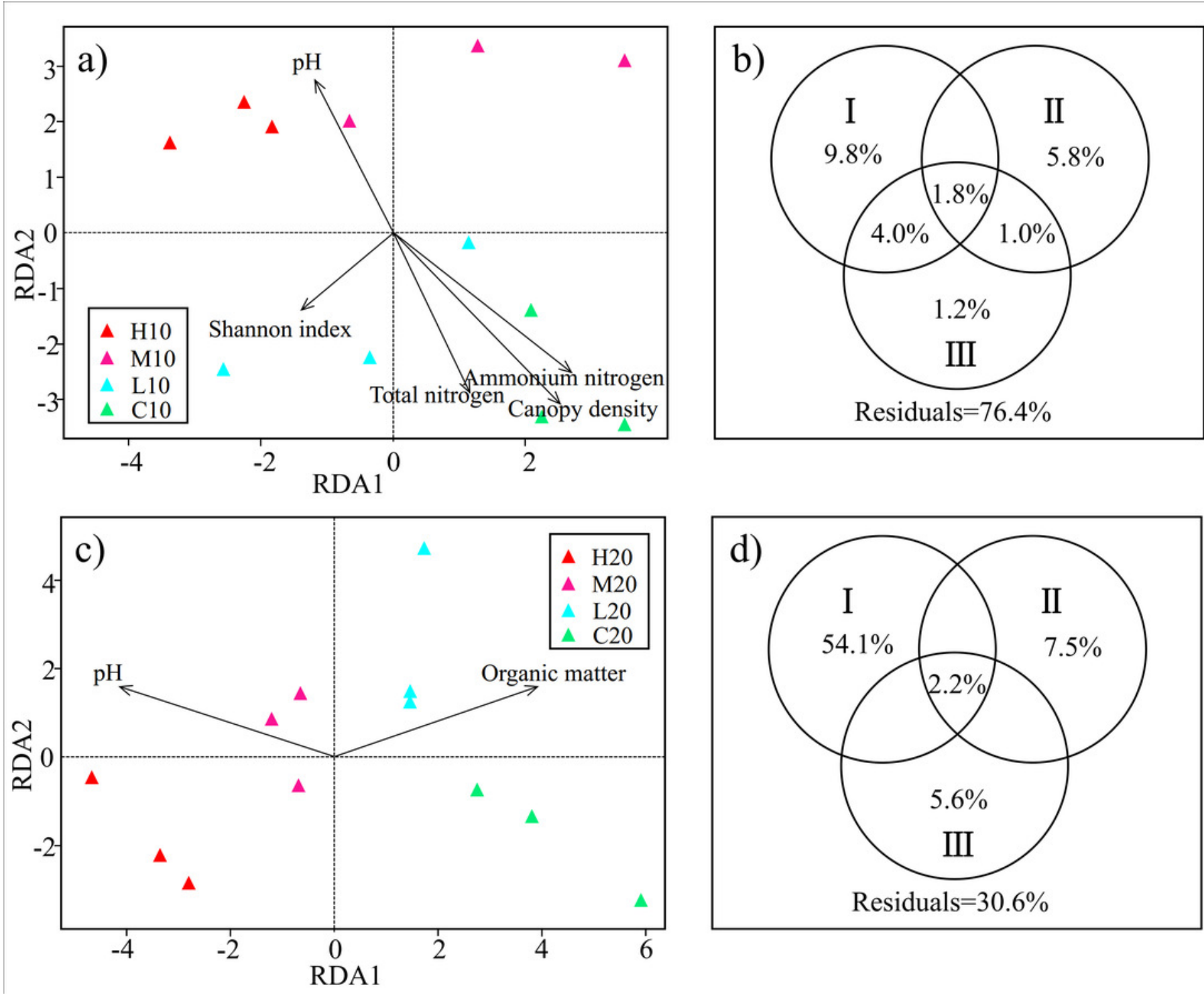


\section{Table $\mathbf{1}$ (on next page)}

Table 1 Criteria for the classification of forest fire severity (Zheng et al., 2012). 


\begin{tabular}{ll}
\hline Fire severity & Criteria for the classification \\
\hline High severity & Trees more than $80 \%$ burns or burned to death, the undergrowth shrubs all consumed, char \\
& height of trunks were more than $5 \mathrm{~m}$. As a result of the ground organic matter all burned, \\
mineral soil color and structure are changed. \\
$10 \%$ to $80 \%$ of the trees were burned and the char height of trunks was between 2 to $5 \mathrm{~m}$. The \\
upper part of forest litter was burned. \\
Trees were burned less than $10 \%$, part of the undergrowth shrubs was consumed (below \\
Low severity & $40 \%$ ), char height of trunks were below $2 \mathrm{~m}$. \\
Control & Unburned
\end{tabular}

2 


\section{Table 2 (on next page)}

Soil physical and chemical properties

Notes: OM, organic matter; $\mathrm{TN}$, total nitrogen; $\mathrm{NH}_{4}{ }^{+} \mathrm{-N}$, ammonium nitrogen; $\mathrm{NO}_{3}{ }^{-} \mathrm{N}$, nitrate nitrogen; SM, soil moisture. Different lowercase letters after the entries indicate significant differences at the same soil depth of different sample plots at $P<0.05$. Values are means \pm standard deviations $(n=3)$. 


\begin{tabular}{|c|c|c|c|c|c|c|c|}
\hline \multirow{2}{*}{$\begin{array}{l}\text { Soil } \\
\text { properties }\end{array}$} & \multirow{2}{*}{ Soil layers } & \multicolumn{4}{|c|}{ Fire severity } & \multicolumn{2}{|c|}{ One-way ANOVA } \\
\hline & & $\begin{array}{c}\text { High } \\
\text { severity }\end{array}$ & $\begin{array}{l}\text { Moderate } \\
\text { severity }\end{array}$ & Low severity & $\begin{array}{l}\text { Unburned } \\
\text { control }\end{array}$ & f-values & p-values \\
\hline \multirow{2}{*}{$\begin{array}{l}\mathrm{OM} \\
\left(\mathrm{mg} \cdot \mathrm{kg}^{-1}\right)\end{array}$} & topsoil & $9190 \pm 90 \mathrm{~b}$ & $17130 \pm 760 \mathrm{a}$ & $17460 \pm 1230 \mathrm{a}$ & $16160 \pm 550 \mathrm{a}$ & 76.11 & 0.000 \\
\hline & subsoil & $4000 \pm 490 \mathrm{~b}$ & $6910 \pm 590 \mathrm{a}$ & $7390 \pm 1180 \mathrm{a}$ & $7920 \pm 440 \mathrm{a}$ & 16.89 & 0.001 \\
\hline \multirow{2}{*}{$\mathrm{TN}\left(\mathrm{mg} \cdot \mathrm{kg}^{-1}\right)$} & topsoil & $310 \pm 10 \mathrm{c}$ & $560 \pm 40 \mathrm{~b}$ & $850 \pm 30 \mathrm{a}$ & $880 \pm 50 \mathrm{a}$ & 171.71 & 0.000 \\
\hline & subsoil & $180 \pm 10 \mathrm{~d}$ & $270 \pm 40 \mathrm{c}$ & $400 \pm 10 \mathrm{~b}$ & $660 \pm 40 \mathrm{a}$ & 169.47 & 0.000 \\
\hline \multirow{2}{*}{$\begin{array}{l}\mathrm{NH}_{4}{ }^{+}-\mathrm{N} \\
\left(\mathrm{mg} \cdot \mathrm{kg}^{-1}\right)\end{array}$} & topsoil & $1.72 \pm 0.03 \mathrm{c}$ & $1.45 \pm 0.37 \mathrm{c}$ & $3.70 \pm 0.62 \mathrm{~b}$ & $19.49 \pm 0.90 \mathrm{a}$ & 674.98 & 0.000 \\
\hline & subsoil & $1.25 \pm 0.30 \mathrm{c}$ & $3.01 \pm 0.68 \mathrm{c}$ & $11.78 \pm 0.67 \mathrm{~b}$ & $16.32 \pm 1.07 \mathrm{a}$ & 285.64 & 0.000 \\
\hline \multirow{3}{*}{$\begin{array}{l}\mathrm{NO}_{3}{ }^{-}-\mathrm{N} \\
\left(\mathrm{mg} \cdot \mathrm{kg}^{-1}\right)\end{array}$} & topsoil & $1.64 \pm 0.43 b$ & $2.45 \pm 0.84 \mathrm{a}$ & $3.56 \pm 0.36 \mathrm{a}$ & $2.64 \pm 0.06 \mathrm{a}$ & 7.29 & 0.011 \\
\hline & subsoil & $2.10 \pm 0.62 b$ & $2.10 \pm 0.44 \mathrm{~b}$ & $3.87 \pm 0.72 \mathrm{a}$ & $3.16 \pm 0.54 \mathrm{a}$ & 6.49 & 0.015 \\
\hline & topsoil & $17.23 \pm 1.20 \mathrm{a}$ & $10.22 \pm 1.44 \mathrm{c}$ & $11.04 \pm 1.31 \mathrm{c}$ & $13.43 \pm 0.68 \mathrm{~b}$ & 20.72 & 0.000 \\
\hline SM (\%) & subsoil & $\begin{array}{l}11.39 \pm 0.10 \\
\mathrm{~b}\end{array}$ & $7.21 \pm 0.68 \mathrm{c}$ & $11.25 \pm 0.99 \mathrm{~b}$ & $15.41 \pm 0.66 \mathrm{a}$ & 71.59 & 0.000 \\
\hline \multirow{2}{*}{ pH } & topsoil & $6.90 \pm 0.27 \mathrm{a}$ & $6.13 \pm 0.12 b$ & $5.68 \pm 0.38 b$ & $5.65 \pm 0.25 \mathrm{~b}$ & 13.89 & 0.002 \\
\hline & subsoil & $6.19 \pm 0.03 \mathrm{a}$ & $5.67 \pm 0.14 \mathrm{a}$ & $5.62 \pm 0.49 \mathrm{a}$ & $5.61 \pm 0.44 \mathrm{a}$ & 2.07 & 0.183 \\
\hline
\end{tabular}

2 Notes: OM, organic matter; $\mathrm{TN}$, total nitrogen; $\mathrm{NH}_{4}{ }^{+}-\mathrm{N}$, ammonium nitrogen; $\mathrm{NO}_{3}{ }^{-}-\mathrm{N}$, nitrate nitrogen; $\mathrm{SM}$,

3 soil moisture. Different lowercase letters after the entries indicate significant differences at the same soil depth

4 of different sample plots at $P<0.05$. Values are means \pm standard deviations $(n=3)$. 